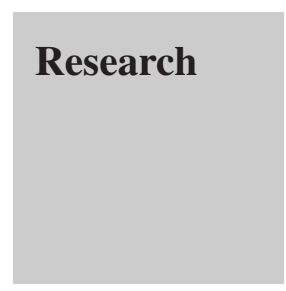

\title{
An Application of Six Sigma to Reduce Waste
}

\author{
Ricardo Bañuelas $^{1}$, Jiju Antony ${ }^{2, *, \dagger}$ and Martin Brace ${ }^{3}$ \\ ${ }^{1}$ Warwick Manufacturing Group, International Manufacturing Centre, University of Warwick, Coventry CV4 7AL, U.K. \\ ${ }^{2}$ Division of Management, Caledonian Business School, Glasgow Caledonian University, Glasgow, U.K. \\ ${ }^{3} 3 M$, Coventry, U.K.
}

Six Sigma has been considered a powerful business strategy that employs a wellstructured continuous improvement methodology to reduce process variability and drive out waste within the business processes using effective application of statistical tools and techniques. Although there is a wider acceptance of Six Sigma in many organizations today, there appears to be virtually no in-depth case study of Six Sigma in the existing literature. This involves how the Six Sigma methodology has been used, how Six Sigma tools and techniques have been applied and how the benefits have been generated. This paper presents a case study illustrating the effective use of Six Sigma to reduce waste in a coating process. It describes in detail how the project was selected and how the Six Sigma methodology was applied. It also shows how various tools and techniques within the Six Sigma methodology have been employed to achieve substantial financial benefits. Copyright (C) 2005 John Wiley \& Sons, Ltd.

KEY WORDS: Six Sigma; quality; case study; statistical tools and techniques; Six Sigma methodology

\section{INTRODUCTION}

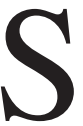
ix Sigma is a quality philosophy that is gaining wide acceptance in the industry ${ }^{1}$. It has followed the TQM movement as the latest thrust for many companies seeking to improve quality, delivery and reduce $\operatorname{costs}^{2}$. Technically, Six Sigma means 3.4 defects per million opportunities (DPMO), where sigma is a term used to represent the variation around the process mean. However, the Six Sigma term has evolved in the last few years as a more complex approach than a simple way to enumerate defects. Linderman et al. ${ }^{1}$ define Six Sigma as 'an organized and systematic method for strategic process improvement and new product and service development that relies on statistical methods and the scientific method to make dramatic reductions in customer defined defect rates'.

The main focus of Six Sigma is to reduce potential variability from processes and products by using a continuous improvement methodology, which follows the phases: define, measure, analyse, improve and control. This approach is known as DMAIC methodology and is employed in tackling problems associated with existing processes/products.

Many organizations have reported significant benefits today as a result of Six Sigma implementation. General Electric and Motorola are probably two of the most successful companies in implementing Six Sigma projects ${ }^{3}$.

*Correspondence to: Jiju Antony, Director of Six Sigma Research Centre, Caledonian Business School, Glasgow Caledonian University, Glasgow, U.K.

†E-mail: j.antony@gcal.ac.uk 
Other companies such as AlliedSignal, Citibank and Sony, have also reported unprecedented success from the Six Sigma initiative ${ }^{3}$.

Although there is a wider acceptance of Six Sigma in many organizations, the growing Six Sigma literature ${ }^{4}$ can be generally categorized as introductory, aimed at educating people about the elementary principles of Six Sigma and selling it as a valuable management philosophy. The current literature fails to demonstrate an in-depth case study showing how Six Sigma projects are carried out in organizations. Rasis et al. ${ }^{5}$ made an attempt producing a fictitious case study. In this paper the authors illustrate the use of DMAIC methodology in a step-by-step fashion to reduce waste in a film-coating process. Due to confidentiality agreement between the company and the authors, the name of the company cannot be revealed in the paper. The paper begins by describing how the project was selected. After that, the different phases of the DMAIC methodology and the tools and techniques employed are given. The paper concludes by highlighting the key benefits and gains achieved from the project.

\section{CASE STUDY}

This case study shows how the DMAIC methodology was used to reduce variability of the selected process.

\subsection{Project selection}

Project selection is the process of evaluating individual projects or groups of projects, and then choosing to implement some set of them so that the objectives of the organization will be achieved ${ }^{6}$. The primary objective of Six Sigma in this case is waste reduction. This effort is linked to the business' critical ' $Y$, (see Brue and Launbry ${ }^{7}$ ) of reducing manufacturing costs. Here the term ' $Y$ ' is the critical to quality characteristic (CTQ), which is defined as the characteristic that is of most importance to any business in strategic terms. Typical examples of ' $Y$ ' (at the top level of a business) may include high customer returns due to poor service or product quality, poor yield for processes which are critical to customers, low profit margin, etc. Having identified this opportunity, the Six Sigma team, formed by one Black Belt and three Green Belts, focused on finding what was preventing one of the coating lines from achieving the business critical ' $Y$ ' goal. This line produces a wide range of coated products for the automotive market. The coating line is a continuous process with equipment designed to allow a non-stop production during roll changes of Web materials and the unloading of finished rolls of production ${ }^{8}$. The Six Sigma team identified the number of line stops (stop offs) in the film coating line and the amount of product wasted as the two important indicators of the line performance. Figure 1 illustrates a Pareto plot for the number of stop offs assigned to different defects.

Each line stop results in a subsequent line start. Waste is generated during a line start, as operational time is needed for the key process to reach steady state running. In order to determine the gap between what the film coating line produces and what is required, a gap analysis was carried out. This analysis, shown in Table I, lists the potential causes that prevent the achievement of the departmental critical ' $Y$ '. The runtime column states the different problems that do not allow the line to run continually. The quality column represents the problems associated with quality issues.

The above causes prevent the coating line from reducing the waste and achieving the desired quality. Therefore, they are also seen as potential areas of improvement. DMAIC Six Sigma methodology is recommended when the cause of the problem is unknown or unclear, the potential of significant savings exists and the project can be done in 4-6 months ${ }^{9}$. To prioritize potential areas of improvement using Six Sigma, the team employed a cause and effect matrix. This matrix, shown in Table II, lists all potential projects or opportunities that are likely to affect the outputs of the process, such as quality, waste and runtime.

\footnotetext{
The basic equation of Six Sigma, $Y=f(x)$, defines the relationship between a dependent variable $(Y)$ or outcomes of a process and independent variables (the $x$ ) or possible causes of problems associated with the process.
} 


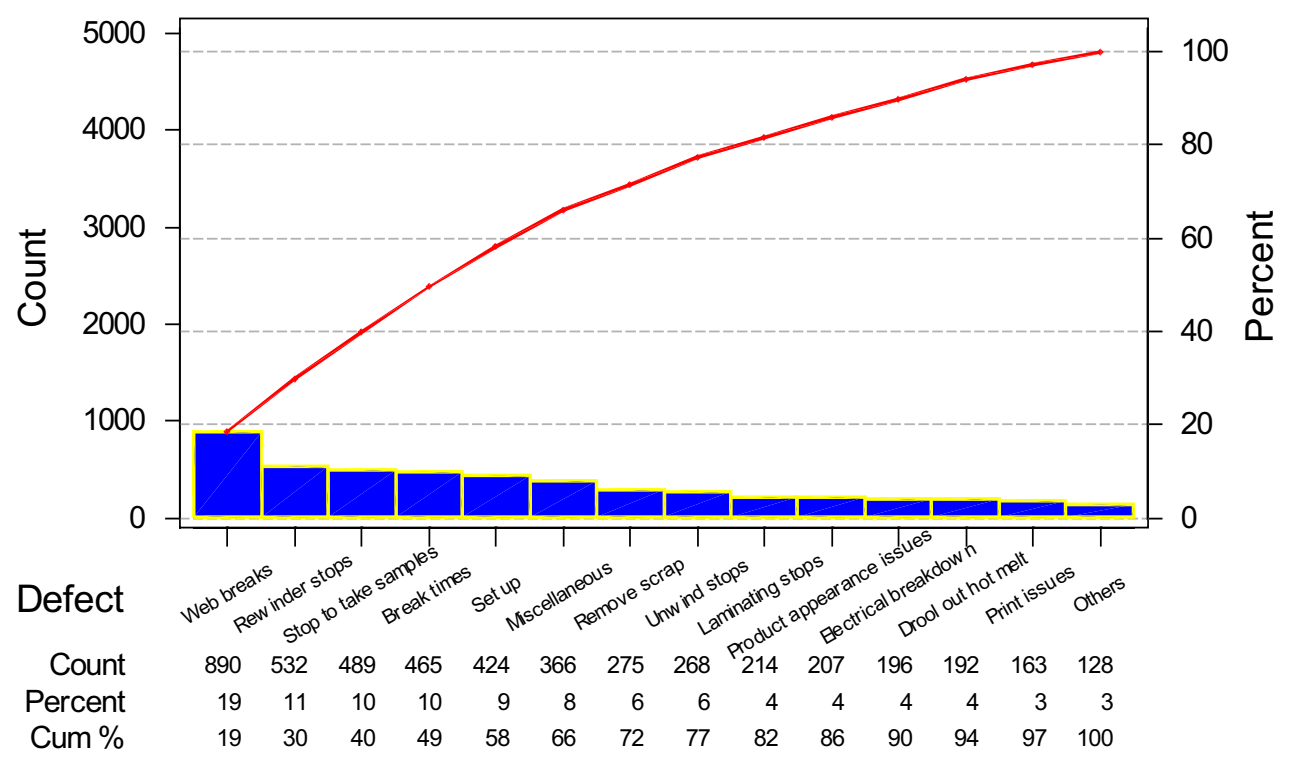

Figure 1. Pareto plot of defects

Table I. Gap analysis based on Q1 2002 data

\begin{tabular}{lcc}
\hline & Runtime gap (\%) & Quality gap (\%) \\
\hline Runtime/Gold Star & 72 & 78 \\
Set/ups & 8.13 & 2.9 \\
Break times & 5.31 & 1.8 \\
Miscellaneous & 5.17 & 3.7 \\
Web breaks & 3.98 & 5.0 \\
Re-winder fails in chop over & 1.73 & 3.6 \\
Appearance problems & 1.71 & 1.4 \\
Poor appearance & 1.70 & 2.3 \\
No print & 0.67 & 1.6 \\
\hline
\end{tabular}

In the cause and effect matrix, outputs are listed in the top row and are assigned values according to the importance to customers and strategic business goals. In this case, they are quality, waste and runtime. A high number indicates more importance. The first column contains the process step where the opportunity exists. At the intersection of each row and column, values are entered to quantify the amount of correlation thought to exist between the inputs ' $X$ ' and outputs ' $Y$ ' ( 9 being strong correlation and 0 no correlation). Numbers in each input are cross-multiplied with the importance number at the top of the column and summed across each row ${ }^{10}$. The opportunities or potential projects and their weightings in the matrix were based on the gap analysis and group expertise during brainstorming sessions.

As a result, a rating for each opportunity provides the guidance that leads the team to select three Green Belt projects. One of the projects has the objective of finding and eliminating the causes of Web breaks. Another is focused on improving product appearance. The third project is focused on identifying, quantifying and eliminating the source of variation that leads to failure due to spindle changes by the re-winder machine. The focus of this paper is on the third project. 
Table II. Cause and effect matrix

\begin{tabular}{llcccc}
\hline & Rating of importance to customer: & 6 & 3 & \multicolumn{1}{c}{1} \\
\hline Process step & \multicolumn{1}{c}{ Process opportunity } & Quality & Start of waste & Runtime & Total \\
\hline Coating & Flow problems & $\mathbf{9}$ & $\mathbf{3}$ & $\mathbf{0}$ & $\mathbf{6 3}$ \\
Coating & Raw material coaster issues & $\mathbf{9}$ & $\mathbf{0}$ & $\mathbf{0}$ & $\mathbf{5 4}$ \\
Rewind & Re-winder bump stop & $\mathbf{3}$ & $\mathbf{9}$ & $\mathbf{3}$ & $\mathbf{4 8}$ \\
Oven sprays & Web breaks & $\mathbf{1}$ & $\mathbf{9}$ & $\mathbf{9}$ & $\mathbf{4 2}$ \\
General & Poor appearance & 6 & 0 & 1 & 37 \\
Print press & No print & 6 & 0 & 1 & 37 \\
General & Poor brushing & 3 & 1 & 3 & 24 \\
General & Mechanical breakdown & 3 & 0 & 0 & 18 \\
Adhesive coating die & Adhesive supply problem & 0 & 3 & 0 & 9 \\
Autosplice & Creases & 1 & 0 & 0 & 6 \\
Print press & Print defects & 1 & 0 & 0 & 6 \\
\hline
\end{tabular}

\subsection{Six Sigma project: re-winder performance}

The turret re-winder at the end of the coating line allows the line to run continuously. It winds up the 'Web' of film in controlled tension producing large rolls of output. It frequently fails to change over from one roll to the other. The purpose of this Green Belt project is to identify, quantify and eliminate the source of variation that leads to failure to change over from one spindle or roll to another by the re-winder machine. The ultimate goal is to improve and sustain re-winder performance with well-executed control plans while reducing manufacturing costs.

As the project deals with the existing process, Six Sigma DMAIC problem solving methodology was applied to the case. The project initially assumes that ${ }^{10-12}$ :

- the design of the turret re-winder is essentially correct;

- customer or delivery partner needs are satisfied with that design; and

- the current product/process configuration satisfies the functional requirements of the market and customer or delivery partner.

The following section describes how the five phases of the Six Sigma (DMAIC) methodology have been applied to the problem at hand. These phases are represented in the roadmap shown in Figure 2.

\subsubsection{Define phase}

This phase aims to define the scope and goals of the improvement project in terms of customer requirements and the process that delivers these requirements ${ }^{13}$. Some of the deliveries of the define phase were incorporated into the project selection. By moving some of the define activity forward into the project selection process the team was able to recognize the company's goals, product-market domain and the basis of the competitive advantage ${ }^{14}$. It was also possible to break down high level ' $Y$ ' into functional strategic areas by understanding the most critical cross-functional activities of the company.

The following four steps were performed during the define phase of the DMAIC methodology:

(1) define the scope and boundaries of the project;

(2) define defects;

(3) define team charter;

(4) estimate the impact of the project in monetary terms.

Define the scope and boundaries of the project

This Green Belt DMAIC project links into a Black Belt project. Black Belt projects are generally broader in scope than Green Belt projects. In this case, the Black Belt project focuses on the total coating line, whilst the Green Belt project is focused on one aspect, the turret re-winder performance. 


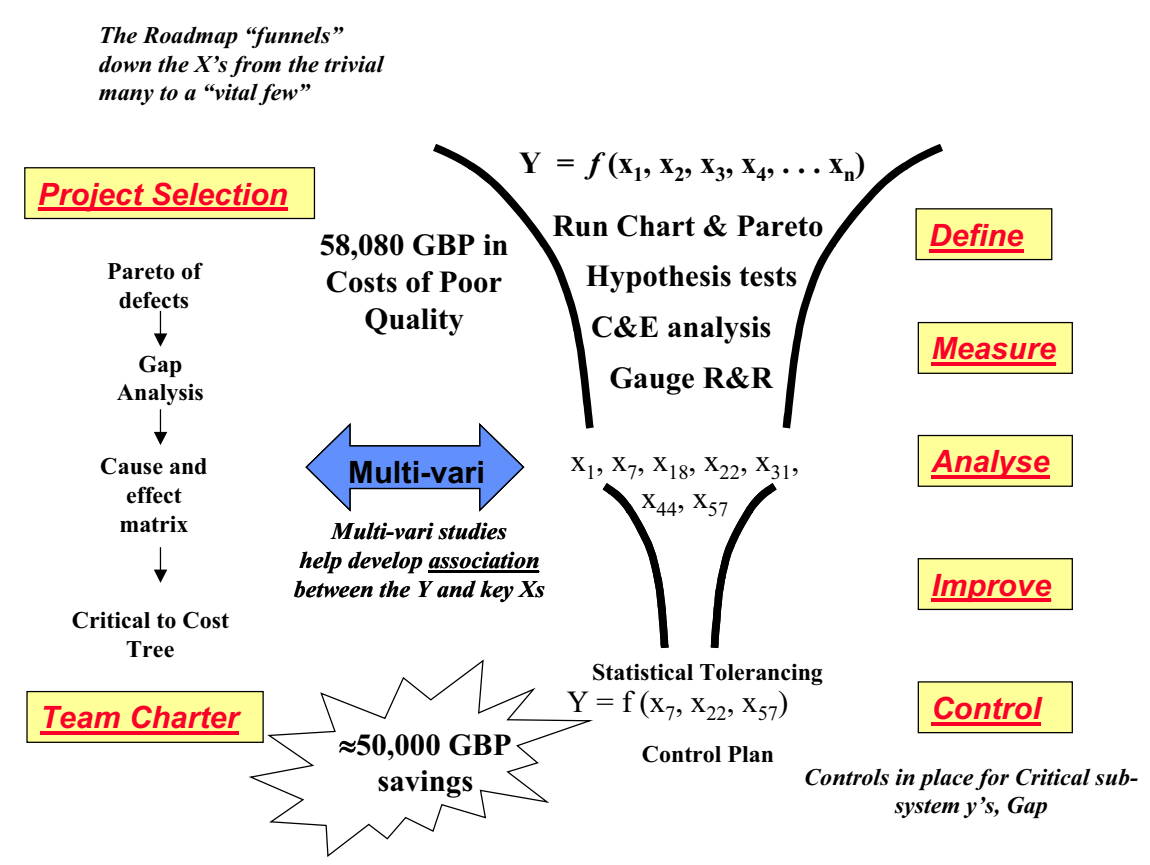

Figure 2. The roadmap

Define defects

The defect is defined as failure of the re-winder to change from one spindle to the other. Each failure results in a loss of Web tension and therefore a line stop.

\section{Define team charter}

Preparing a project charter requires team members to identify the following partially redundant elements; such redundancy in the elements helps team members distil the critical elements of the business case ${ }^{5}$. The project charter was carried out to state the opportunity that exists. It summarizes the define stage from the business critical ' $Y$ ' and its linkage to the project ' $Y$ '. It also cascades down the project description, goals and potential financial benefits.

Element 1: Process definition. Element 1 aims at defining the process in which opportunity exists. This project is concerned about the performance of the re-winder chop-over process.

Element 2: Business critical ' $Y$ '. This element describes the opportunity as it relates to the strategic business goal $^{5}$. The critical quality/delivery/cost tree helps Six Sigma teams to move from general needs of the customers or business strategy to the more specific requirements ${ }^{15}$. Figure 3 depicts how generic business goals cascade into more specific potential Six Sigma projects. In this case, the critical business ' $Y$ ' is to reduce manufacturing costs. From this high-level business, ' $Y$ ' flows down the project ' $Y$ ', which focuses on identifying, quantifying and eliminating the source of variation that leads to failure of the turret re-winder.

Element 3: benefit impact. Six Sigma begins and ends with customers. Projects should begin with the determination of customer requirements and it is essential to set project goals based on reducing the gap between the company's deliveries such as quality, delivery time, reliability and $\operatorname{cost}^{16}$. In this element, the anticipated impact of the project on overall business performance is estimated. Accordingly, the potential impact of the project is estimated based on three fundamental metrics: baseline performance, project goals and process entitlement. The Six Sigma project team decided that the re-winder should allow no more than its entitlement (i.e. three failures per week). As a result, the calculated opportunities in financial terms are estimated from current performance (baseline) minus the targeted goals of the projects (refer to Table III). 


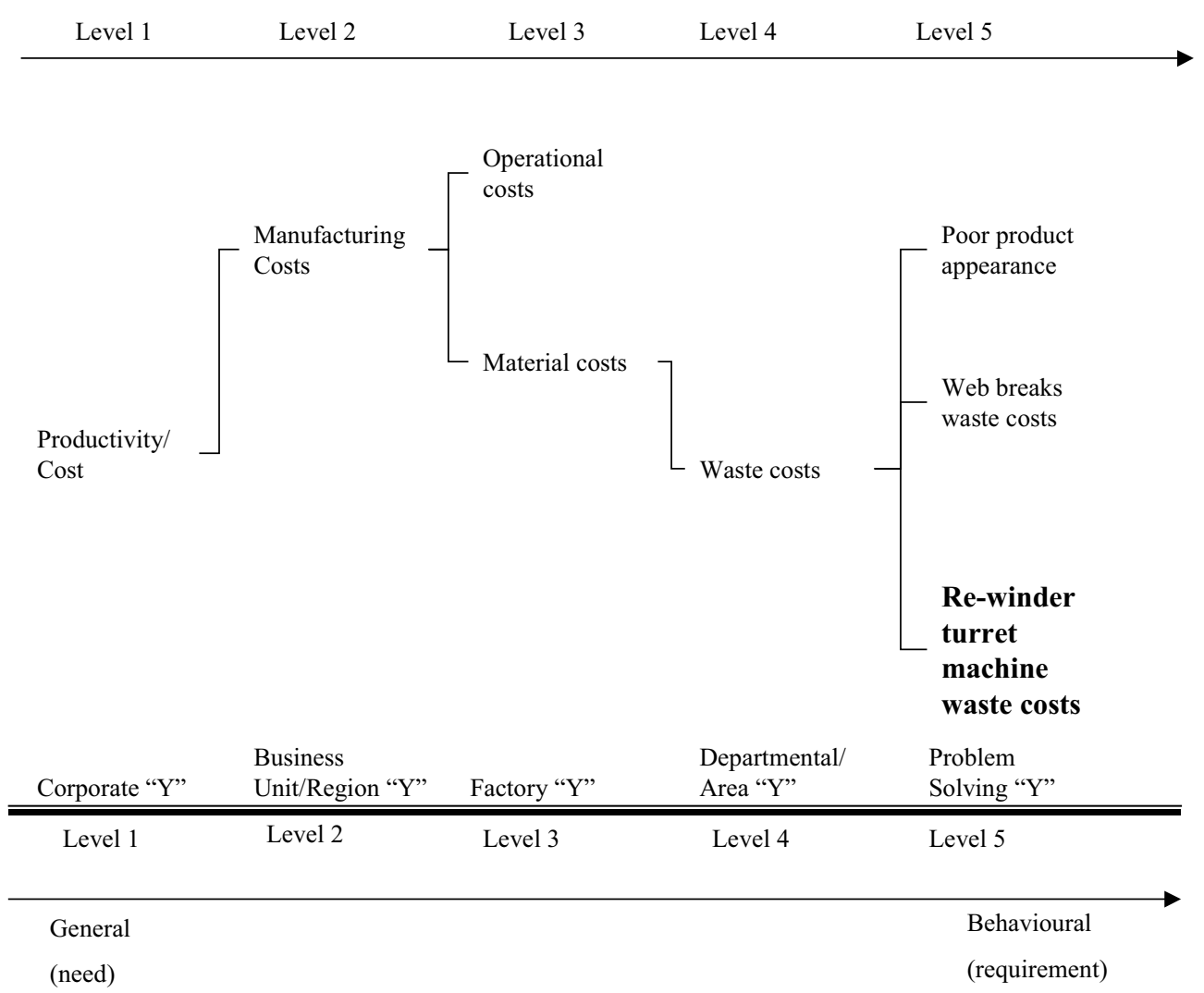

Figure 3. Critical to cost tree

Table III. Estimated financial benefits

\begin{tabular}{lcccc}
\hline & Baseline & Goal & Entitlement & Units \\
\hline Stop offs & 11 & 3 & 3 & Occ/week or $\mathrm{m}^{2}$ \\
$\%$ Gold Star & 63 & 75 & 75 & $\%$ \\
Cost of poor quality & $£ 1210$ & $£ 330$ & $£ 11$ & 1 stop off $=80 \mathrm{~m}$ \\
& & & & \\
Total opportunity $£ 58080$ & & & \\
(Annual) saving goal $£ 42240$ & & & \\
(based on 48 weeks) & & & \\
\hline
\end{tabular}

Element 4: describe the scope and boundaries of the project. This project is limited to the re-winder and excludes line stops associated with other causes.

Element 5: list the key milestones activities with dates. The team decided to consider the DMAIC roadmap to list the key milestones of the projects. Accordingly, the following phases were established with targeted dates to completion.

Element 6: support required. In this element the team stated the support required from different departments. They highlighted the importance of obtaining maintenance expertise as a key to the success of this project.

Element 7: core team members. The Six Sigma team in this case is a cross-functional one, consisting of a champion, a process owner, a Master Black Belt, a Black Belt, a Green Belt and six team members (people from maintenance, operators and a line supervisor). 
Because subsequent Six Sigma process steps of the DMAIC methodology are built upon work completed during the define phase, the Six Sigma team ensured that the following deliveries were achieved before proceeding to the next phase:

- process linked to strategic business requirements;

- customer and critical-to-quality characteristics identified;

- linkage of customer requirements to process outputs;

- team formed with charter describing purpose, project plan, goals and benefits of the project;

- financial benefits identified and calculated.

The Six Sigma team agreed to the listed deliveries and proceeded to the measure phase.

\subsubsection{Measure phase}

The measure phase has the purpose of mapping the current process and establishing metrics that describe the project ' $Y$ ' in order to narrow the problem to its major factors or 'vital few' root causes ${ }^{17}$.

\section{Map process and identify process inputs and outputs}

Process mapping provides a picture of the steps that are needed to create the output or process ' $Y$ '. It is a pictorial representation of the process, which helps to identify all value added and non-value added process steps, key process inputs (' $X$ ') and outputs (' $Y$ ' $)^{18}$. There are different tools suitable for process mapping, such as the flow chart, the SIPOC (supplier, input, process, output, customer) diagram and standard operation procedures (SOPs). In this case, a process map was generated using a SOP format. This format facilitates the understanding of the re-winder operation through a visual representation of the steps followed during this operation. The SOP was used throughout the course of the project as a reference (refer to Figure 4).

\section{Establish baseline process capability}

A baseline indicates the current status of the process performance ${ }^{7}$. The metric established for the re-winder's performance is a passed or failed chop-over (discrete data). From the manufacturing database the current process performance at a level of $1.2 \sigma$ or $88.5 \%$ yields in the long term.

To record and display trends over time and detect meaningful changes in the process, a run chart was created for the fraction of non-conforming chop-overs ${ }^{19}$. However, it showed no apparent ranking in failures over time. To recognize any possible trend in failures within the re-winder process, a Pareto plot of defects was generated ${ }^{19}$. Pareto charts create awareness for tackling the most pressing products first ${ }^{20}$. It can be said from the Pareto analysis in Figure 5 that most of the products have a similar fraction of non-conformities. Therefore, it is difficult to assign any relationship between process and product performance.

Initially, the project ' $Y$ ' metric was discrete (i.e. pass/fail). The team strive to choose continuous data information over discrete information whenever possible, because continuous information provides more information for a given sample size ${ }^{18}$. However, the sample size required to deal with the fraction of nonconforming as continuous data can be large, especially for low non-conforming rates ${ }^{18}$. The re-winder Web cutting operation time seemed to be a good predictor of the operation outcome. The longer the operation cycle time, the higher the probability of failure. Conversely, when the cutting operation functioned properly, the cut cycle time appeared lower than that of the failures, as the box plot in Figure 6 illustrates.

To be statistically confident that the cut cycle times were different for a successful chop-over versus an unsuccessful chop-over, a hypothesis ${ }^{\S}$ test was carried out ${ }^{21}$. In order to arrive at a valid conclusion a $t$-test was carried out with the following hypothesis:

$H_{0}: \bar{x}_{1}=\bar{x}_{2}$ means of cutting operation time are the same

$H_{1}: \bar{x}_{1} \neq \bar{x}_{2}$ means of cutting operation time are different

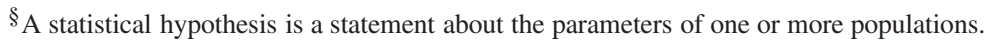




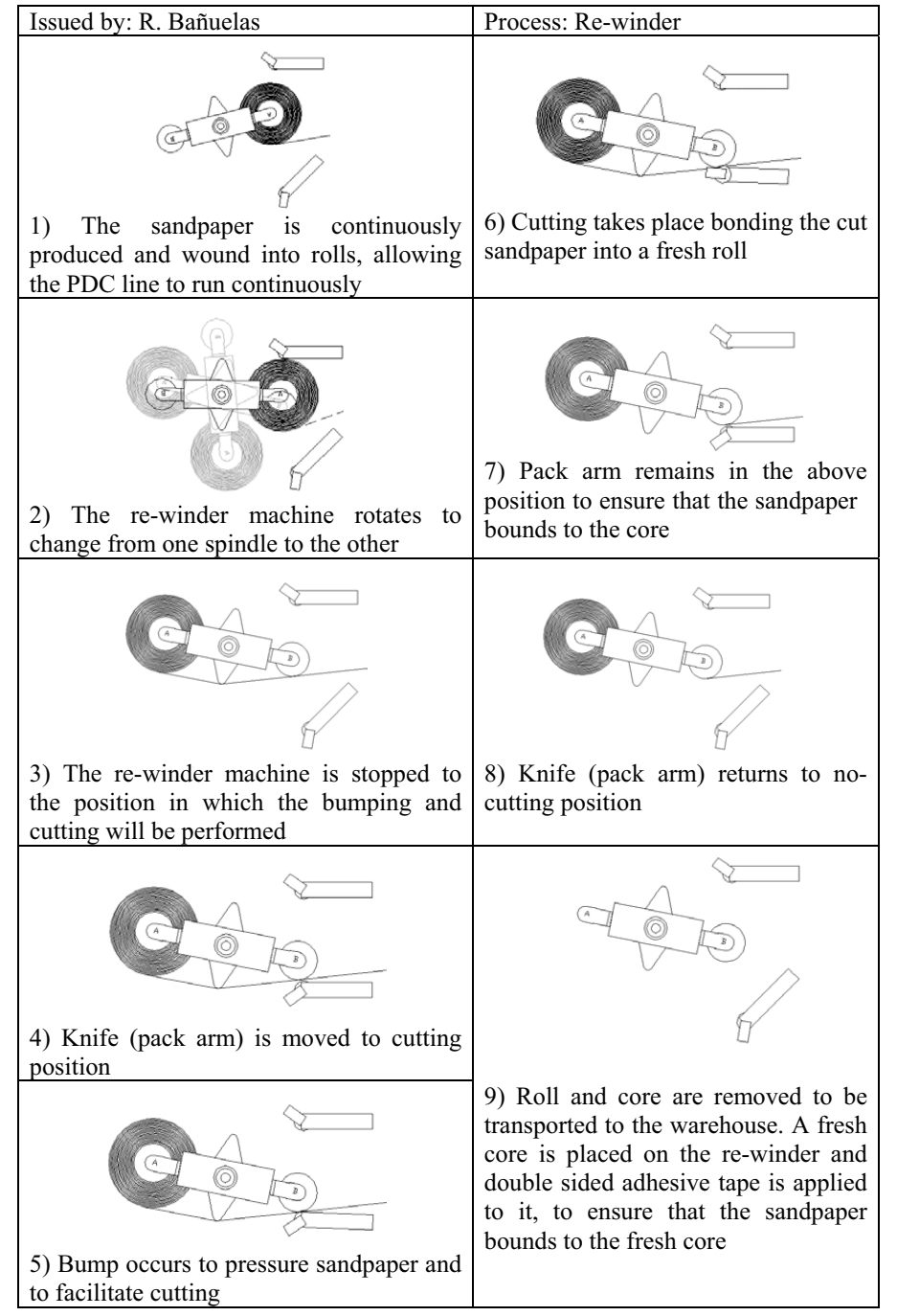

Figure 4. Process mapping

The hypothesis test was carried out at 5\% significance level and 5\% power. As the $p$-value was much lower than the significance level (5\%), it was concluded that there was a significant difference in cut cycle time when the operation failed. From the hypothesis test, the team concluded that cut cycle time would be a good predictor of success in the winder operation. However, the measurement system needs to be analysed to evaluate its potential capability.

\section{Establish measurement system capability}

Gauge R\&R analysis was carried out to assess how much variation is associated with the measurement system ${ }^{19}$. According to gauge $R \& R$ analysis, the variation in measurement is sub-divided into variation due to repeatability and variation due to reproducibility ${ }^{19,22}$. The measurement system in this case has a sigma of 4.7892 , which is formed by a sigma reproducibility of 0.8339 and a sigma repeatability of 4.8612 . Thus, the repeatability is the main contributor to measurement system inconsistency. The sigma total is 27.907 , producing a precision to total ratio of $0.1742(4.81 / 27.907)$ that can be considered as marginal ${ }^{19}$. Therefore, the proposed measuring system shows a relative good measurement system capability. 


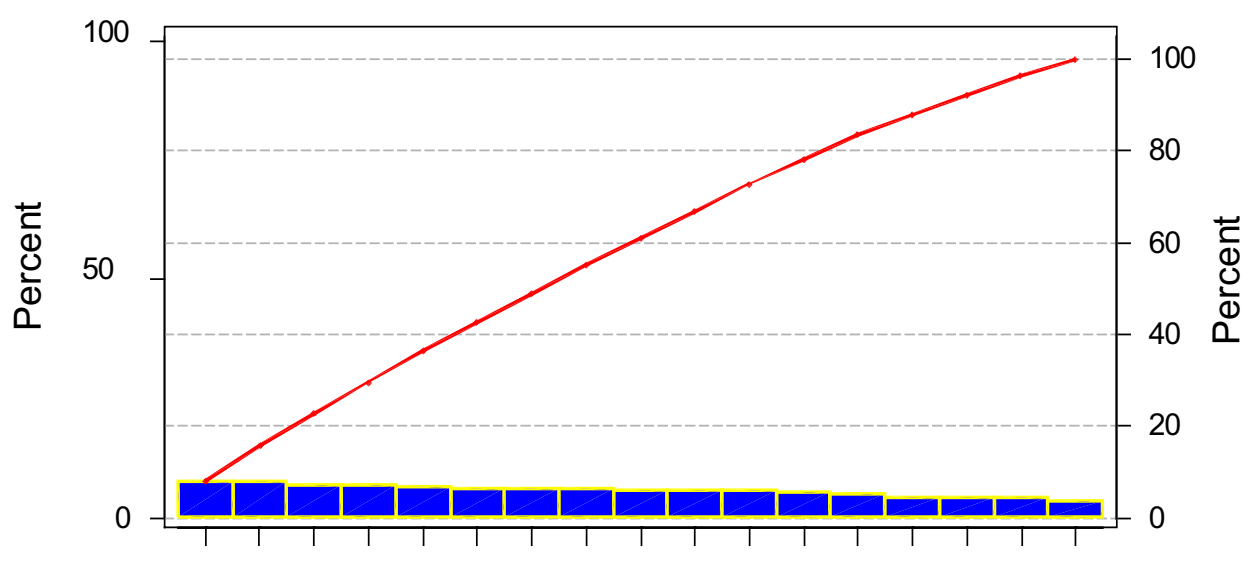

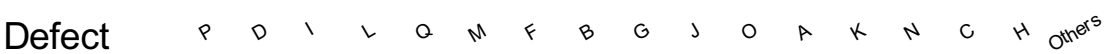

Count $\quad$ 15.2514.8313.3113.3113.0212.3012.0411.7711.4411.3811.3710.42 $9.998 .53 \quad 8.47 \quad 8.36 \quad 6.63$

$\begin{array}{llllllllllllllllll}\text { Percent } & 8 & 8 & 7 & 7 & 7 & 6 & 6 & 6 & 6 & 6 & 6 & 5 & 5 & 4 & 4 & 4 & 3\end{array}$

$\begin{array}{llllllllllllllllll}\text { Cum } \% & 8 & 16 & 23 & 29 & 36 & 43 & 49 & 55 & 61 & 67 & 73 & 78 & 83 & 88 & 92 & 97 & 100\end{array}$

Figure 5. Re-winder Pareto

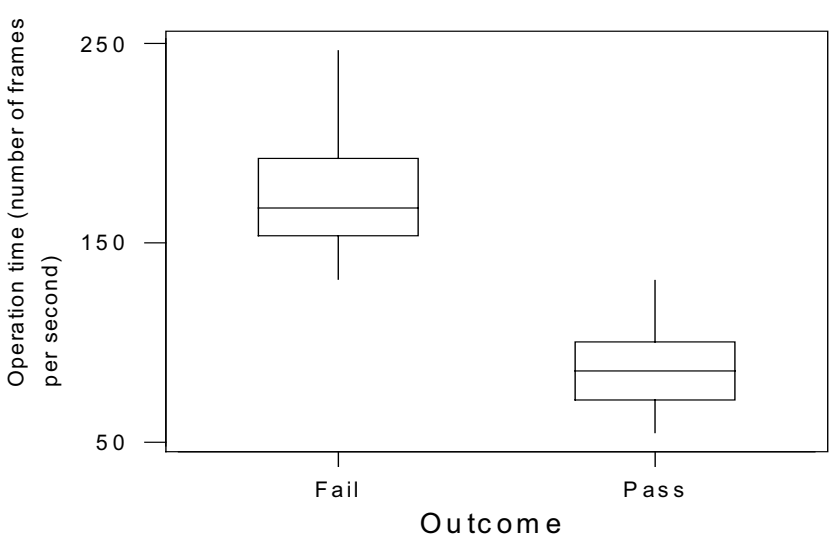

Figure 6. Box plot for operation time

\section{Cause and effect analysis}

Having mapped the process, the team proceeded to analyse the potential causes of failure. Although this task is carried out in detail during the analysis phase, the team decided to start to discern the causes of the problem in order to identify the ' $X$ ' to measure. Cause and effect analysis was carried out to illustrate the various causes that affect the re-winder performance ${ }^{23}$. Figure 7 illustrates the potential causes that could generate a failure in the re-winder cutting operation. The potential causes $(X)$ were identified in a team brainstorming session (manufacturing engineers, maintenance team, line operators and supervisors) ${ }^{18}$. Figure 7 indicates that the majority of potential causes are associated with the re-winder itself and the type of product. In total, 21 ' $X$ ' were identified, which formed the input of the data collection plan to construct the multi-vari study.

\section{Data collection plan}

Having established the current process performance and created a continuous project ' $Y$ ' metric, the Six Sigma team focused on understanding the relationships between changes in the downstream factors (' $X$ ') and their impact on the outcome (' $Y$ '). To achieve this, potential predictors (' $X$ ') of the project ' $Y$ ' were identified during 


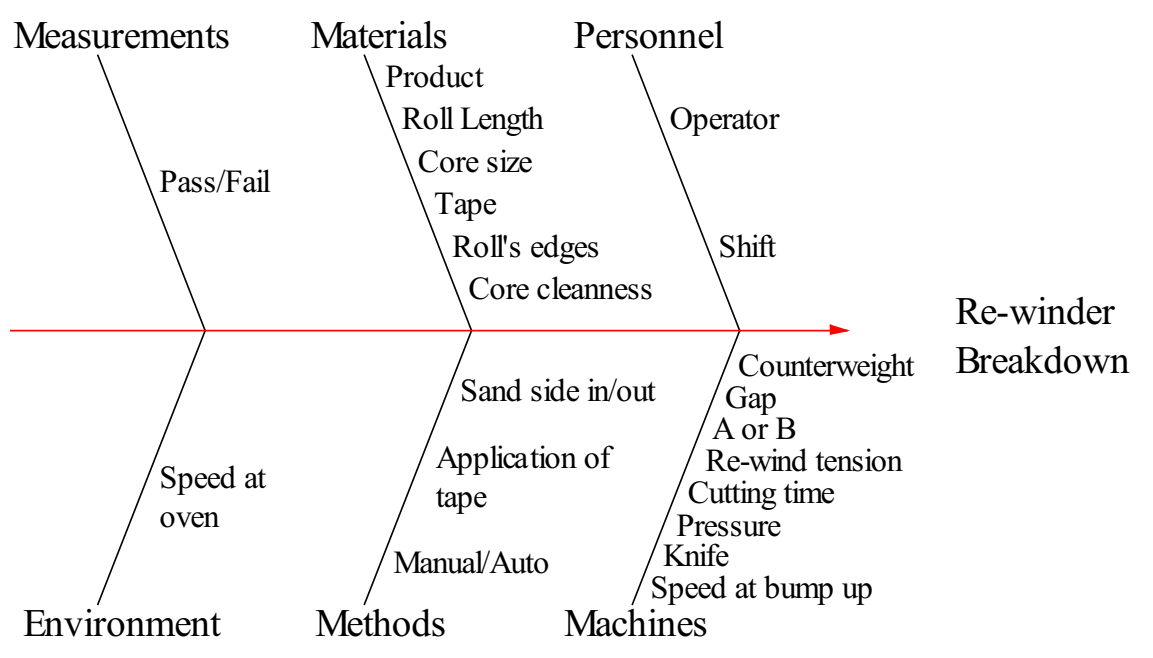

Figure 7. Cause and effect diagram for re-winder

the cause and effect diagram. However, for most of them there was no information available. A data collection plan was carried out to obtain this information. The data collection plan included the ' $X$ ' to measure, their operational definitions, identification of data sources and data collection forms ${ }^{15}$.

As an outcome of the measure phase, the Six Sigma team narrowed its focus on distinct groups of project issues and opportunities. After the completion of the measure phase the team achieved the following:

- plan for collecting data that specifies the data type and collection technique;

- validated measurement system that ensures repeatability and reproducibility;

- set of preliminary analysis results that provides project direction;

- baseline measurement of current performance.

\subsubsection{Analyse phase}

The purpose of the analyse phase is to start learning about data in order to generate, segment, prioritize and verify the possible root causes and their relationship to the ' $Y$ ' or outputs $^{24}$. The data collected from the measure phase served as an input for the analysis phase. Because the data collection was carried out for a relatively long period of time, it allowed the process to reveal its full-range variation on a long-term basis.

Different tools and techniques were employed to find correlation between ' $X$ ' and project ' $Y$ ' in order to reduce the number of variables and select the 'vital few' for further analysis. Main effects plots were employed to $\log$ data means for different ' $X$ '. The points in the plot are the means of the response variable at various levels of each ' $X$ ', with a reference line drawn at the grand mean of the response data (cut cycle time) ${ }^{25}$. They were used for comparing magnitudes of the different ' $X$ ' on the response. It is important to mention that they are not the result of a design of experiment, but the result of the data collection in which different variables or factors were recorded on a wide range of levels.

Figure 8 shows a main effect plot for five different ' $X$ ' at different levels and their influence in cut cycle time. The result shown in Figure 8 confirms that the knife or unit where the cut operation is performed seems to be a significant contributor to the cutting time performance. Chop-overs on top unit (knife) average 70 units of time lower than the bottom unit. This corresponds to a better performance on the top unit ( $8.53 \%$ defect rate) in comparison to that of the bottom unit ( $10.55 \%$ defect rate). Investigation revealed that the difference in cut operational time between the bump and cut cycle on the bottom can be attributed to a possible difference in the pneumatic system in both units, the top unit having more recent pneumatic controls. The team decided to update the pneumatics in the bottom unit to match those in the top unit. After the replacement of the pneumatic system 


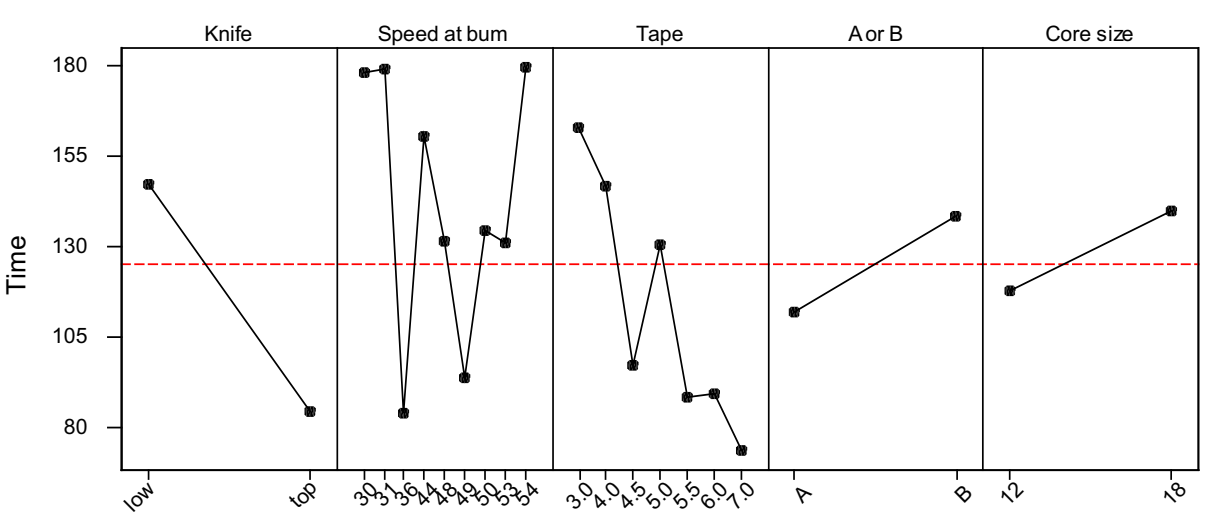

Figure 8. Main effects plot-data means for time

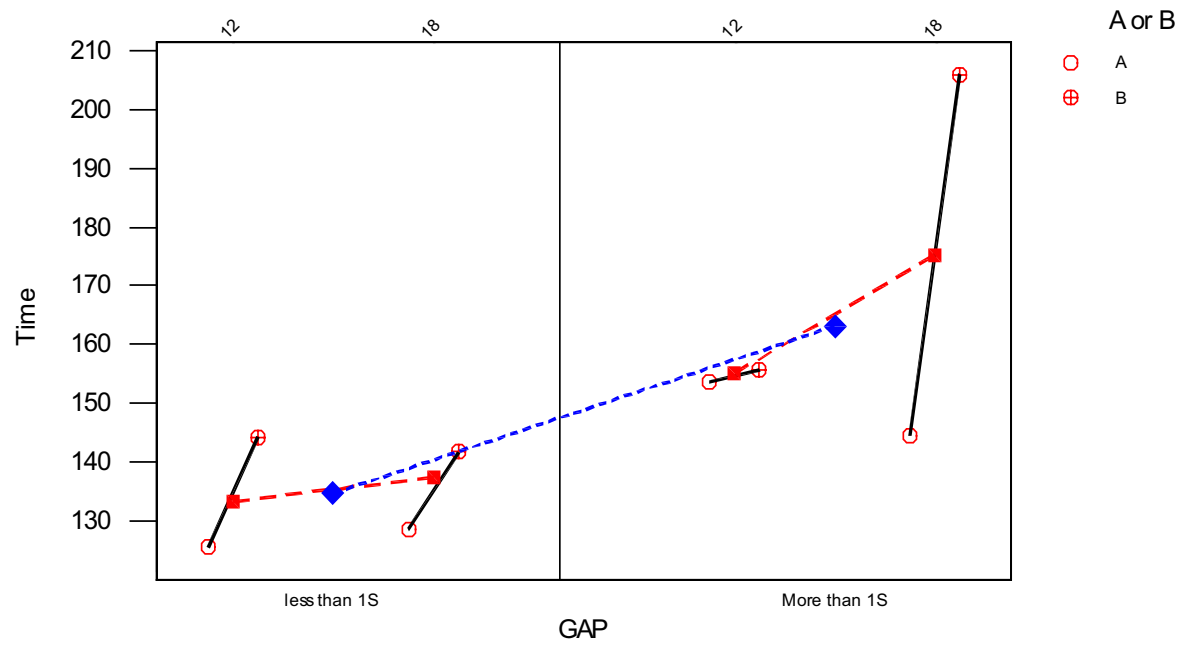

Figure 9. Multi-vari chart for time by A or B gap core size

the bump delay was eliminated and consequently a drop in the failure rate was achieved. However, it proved that there was more than one ' $X$ ' contributing to failures, since failures still occurred.

The multi-vari chart shown in Figure 9 was carried out to determine the interaction between gap, spindle and core size. Multi-vari studies help associate key ' $X$ ' and the project ' $Y$ ', identify noise variables and reduce the number of ' $X$ ' for the improvement phase. In addition, they are helpful in obtaining and understanding the process during its natural variation ${ }^{7}$. The left-hand side of Figure 9 shows the process performance when the gap variation is less than one standard deviation. As it can be seen, better performance (smaller the better) is recorded under this scenario. On the other hand, when gap is outside one standard deviation the cutting operation time increases.

From the information obtained from the main effects plot and the multi-vari chart, the team decided to concentrate on the gap between the new core (primed position) and the knife. The maintenance team confirmed that the gap is determined by the stop position. A cam limit switch set-up controls the re-winder turret position. It was thought that the gap between the new core and the knife would be critical to the re-winder performance. If the gap is too small, the arm with the knife reaches the new core before the Web is cut, causing a failure. Conversely, when the gap is too large, the knife is able to cut through the Web properly but the pack arm fails to press the Web onto the new core and so when the pack arm moves out of position the Web moves from the core and a failure occurs due to the lack of a bond between the new core and the Web. The theory is backed by the 
information shown in Figure 9. The limit switch system makes the re-winder turret stop in a specific position depending on the unit (top or bottom), spindle (' $A$ ' or ' $B$ ') and core size (12" or $\left.18^{\prime \prime}\right)$. However, inertia from the turret rotation and counterweight from the outgoing full roll may affect and modify this position after the limit switches system sends the stop signal. Further analysis is needed to determine if the gap variable is now the critical ' $X$ ' and to establish the correct level setting of this subsystem critical to quality characteristic.

Having carried out the data collection plan and analysing the data with the aid of multi-vari charts, an hypothesis test, gauge R\&R, basic descriptive statistics and main effects plot, some ' $X$ ' were discarded for further analysis (e.g. operator, shift, pressure, line speed) and others were selected to form part of the vital few (gap, core size, spindle, unit/knife). As an outcome of the analysis phase, the Six Sigma team members had a strong understanding of the factors impacting their project, including:

- key process input variables or the vital few ' $X$ ' that impact the ' $Y$ ';

- sources of variation (i.e. where the greatest degree of variation exists).

\subsubsection{Improve phase}

The improvement phase has the objective of considering the causes found in the analysis phase, and also selecting and targeting solutions to eliminate such causes. The multi-vari study helped us to understand the relationship among different factors and we concluded that the gap factor may be considered an important source of variation. Consequently, the team was primarily concerned with the capability and the specification limits of this subsystem critical to quality characteristic.

2.2.4.1. Statistical tolerance. From the multi-vari study, it was found that the gap between the re-winder's pack arm and the new core has a significant impact on the outcome. Statistical tolerance of the gap was carried out to determine the probability of system failure based on the actual variation of the parts. The ultimate objective was to identify the sources of variation in the gap position and possible ways to eliminate it. Statistical tolerance analysis was carried out because there was no knowledge of the appropriate gap at which the re-winder machine should be set and its capability was also unknown.

\section{Sub-system CTQ 'gap' capability}

To establish the range of acceptability and capability of the gap, samples were taken including all possible combinations between core sizes (12" and $18^{\prime \prime}$ ), spindles (A and B) and re-winder's units (top and bottom). As a result, it was concluded that every time the gap is above 1.200 and below 0.350 inches, the machine fails.

Having identified the upper and lower specification limits of the CTQ characteristic 'gap', we can predict the process capability in the short and long term estimated by the sigma level. 'Rational Subgrouping' was used to separate sigma short term and sigma long term as recommended by Eckvall and Juran ${ }^{26}$ and used by Harry ${ }^{27}$ to calculate the 1.5 shift. The 'rational subgrouping' technique quantifies the group-to-group variation by the segregating product/process from different streams (e.g. core size, spindle). Once segregated, the data for each group can be treated in a conventional manner. The combined effect of group-to-group and within-group variation is expressed by the formula

$$
\sigma_{\mathrm{c}}^{2}=\sigma_{\mathrm{w}}^{2}+\sigma_{\mathrm{b}}^{2}
$$

where $\sigma_{\mathrm{c}}$ is the composite variation, $\sigma_{\mathrm{w}}$ is the within-group variation and $\sigma_{\mathrm{b}}$ is the group-to-group variation. This equation is valid only if there is no interaction between the two variables. The variations in the above formula can be estimated by the square root of the mean square error term in the ANOVA table (Table V).

Accordingly, to estimate the short- and long-term sigma capability, rational subgrouping was employed in a way that appears likely to give the maximum chance for the measurements of within subgroups to be alike and the maximum chance for between subgroups to differ, one over the other. Thus, subgroups were selected based on the cause and effect diagram and the multi-vari study in which it is believed that different core sizes and spindles affect the gap. The subgroups were selected for the combinations of spindle (A or B) and core size $\left(12^{\prime \prime}, 18^{\prime \prime}\right)$ and samples of ten were taken consecutively to reduce the dispersion in the subgroup (Table IV). However, in other instances the process becomes complex and the analysis to measure process shifts 
Table IV. Rational subgroups

\begin{tabular}{lcrrrr}
\hline & A-18 & A-12 & B-18 & B-12 & All \\
\hline & 0.7040 & 0.3320 & 0.9820 & 1.0933 & 3.1113 \\
& 0.8391 & 0.6660 & 1.2625 & 0.9906 & 3.7582 \\
& 0.6891 & 0.6769 & 1.2247 & 0.7396 & 3.3303 \\
& 0.7592 & 0.4899 & 1.1302 & 0.8586 & 3.2379 \\
& 0.8054 & 0.2858 & 0.9832 & 0.8749 & 2.9493 \\
& 0.6996 & 0.5290 & 1.1797 & 0.9113 & 3.3196 \\
& 0.8272 & 0.5196 & 1.0775 & 0.8820 & 3.3063 \\
& 0.7104 & 0.8578 & 1.1088 & 0.9313 & 3.6083 \\
& 0.5688 & 0.4610 & 1.2775 & 0.9672 & 3.2745 \\
$\sum y$ & 0.7211 & 0.3412 & 1.0712 & 0.9009 & 3.0344 \\
$\bar{y}$ & 7.3239 & 5.1592 & 11.2973 & 9.1497 & 32.9301 \\
$\sum y^{2}$ & 0.7324 & 0.5159 & 1.1297 & 0.9150 & 3.2930 \\
$\left(\sum y\right)^{2} / n$ & 5.4215 & 2.9482 & 12.8638 & 8.4491 & 29.6826 \\
Sum of squares & 5.3639 & 2.6617 & 12.7629 & 8.3717 & 27.1098 \\
of deviations $=\sum y^{2}-\left(\sum y\right)^{2} / n$ & 0.0576 & 0.2865 & 0.1009 & 0.0774 & 2.57278 \\
\hline
\end{tabular}

Table V. ANOVA table

\begin{tabular}{lcrccccc}
\hline Source of variation & SS & df & MS & MS $^{1 / 2}$ & $F$ & $p$-value & $F_{\text {crit }}$ \\
\hline Between operators & 2.05050 & 3 & 0.68350 & 0.82674 & 47.1126 & $1.51 \mathrm{E}-12$ & 2.866265 \\
Within operator & 0.52228 & 36 & 0.01451 & 0.12045 & & & \\
Total & 2.57278 & 39 & & & & & \\
\hline
\end{tabular}

and capability also becomes complex. Eckavall and Juran ${ }^{26}$ proposed several methods of analysis to assist in quantifying different components of variation to calculate the process shift. These methods include the multivari graph, design of experiments and response surface.

During this case, in order to obtain the sigma short term, the variation within subgroups or streams was calculated by estimating the square root of the mean square error term of the ANOVA shown in Table V.

Sigma short term assumes each subgroup average is centred; so all subgroup means are artificially centred to a target value. Thus, it can be calculated for either one of the specification limits (SLs):

$$
\sigma_{\mathrm{st}}=\frac{S L-\text { target }}{\sigma_{\mathrm{w}}}
$$

By substituting

$$
\sigma_{\mathrm{st}}=\frac{1.2-0.775}{0.1205}=3.52 \approx 216 \mathrm{DPMO}
$$

the sigma level long term, which describes the sustained reproducibility of a process, is estimated by

$$
\begin{aligned}
& \sigma_{\mathrm{lt}}=\operatorname{Min}\left[\frac{U S L-\mu}{\sigma_{\mathrm{t}}}, \frac{\mu-L S L}{\sigma_{\mathrm{t}}}\right] \\
& \sigma_{\mathrm{lt}}=\operatorname{Min}\left[\left(\frac{1.200-0.8232}{0.2563}\right) \cdot\left(\frac{0.8232-0.3500}{0.2563}\right)\right]=\operatorname{Min}(1.4701,1.8461)=1.4701 \\
& \sigma_{\mathrm{lt}}=1.4701 \approx 70785 \mathrm{DPMO}
\end{aligned}
$$




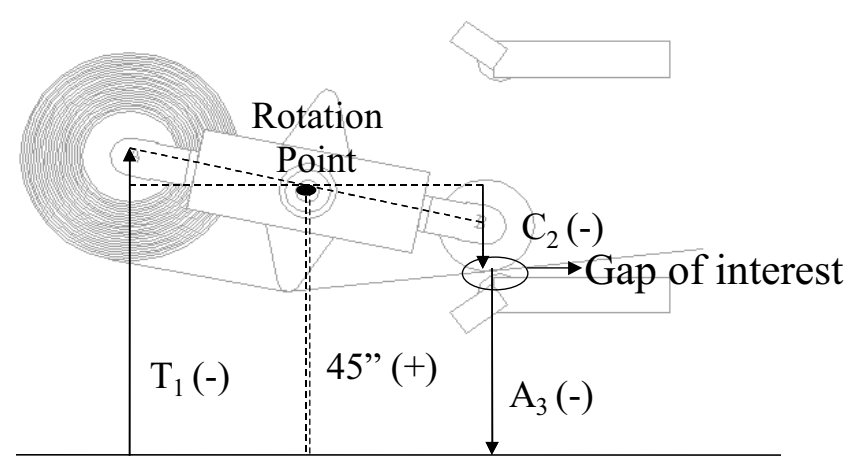

Figure 10. Vector diagram

The sigma shift describes how well the process being measured is controlled over time. It can be calculated by the difference between the sigma level short term and long term, as follows:

$$
\begin{aligned}
& \sigma_{\text {shift }}=\sigma_{\text {st }}-\sigma_{\mathrm{lt}} \\
& \sigma_{\text {shift }}=3.5200-1.4701=2.0499
\end{aligned}
$$

For the process under study, the shift is thus estimated to be 2.0499 and hence the assumption based on the literature ${ }^{15,18,22,27}$ of 1.5 sigma shift was not appropriate.

\section{Gap's transfer function}

The gap is affected by three different factors: (T1), the variability of the turret to reach the bump position; (C2), the variability in core size; and (A3), the variability of the bump unit or pack arm to reach the bump position (Figure 10).

In statistical tolerance, the system capability calculated above consists of the capabilities of multiple parts and dimensions which make up the system. Therefore, the parts' capabilities dictate the system capability predicted previously. To define what statistical method to employ in statistical tolerancing, the first step is to verify that the parts' dimensions are independent and normal distributed ${ }^{26}$. From an engineering point of view, the parts' independency was confirmed. In addition, each part was checked for normality using Anderson-Darling and Ryan-Joiner tests. The $p$-values of the tests in three parts and in both tests were greater than $5 \%$ significance level, thus $H_{0}$ was accepted (i.e. data are assumed to be normal).

To relate the subsystem CTQ 'gap' to lower level components, a vector loop was carried out. The vector loop diagram shows the relationships of the multiple components (T1, C2, A3) in the sub-system gap. Figure 10 depicts the diagram. Accordingly, an increase in any of the component dimensions decreases the gap. For example, if the core size increases, the gap between the core and the knife or arm decreases. In addition, if the re-winder rotates clockwise (T1 increases), the gap decreases.

The transfer function of the subsystem critical to the quality characteristic 'gap' is described statistically by $\mu_{\text {gap }}$ and $\sigma_{\text {gap }}$. These are calculated based on the means and standard deviations of the part dimensions that form the gap. Because the dimensions of the variables are independent, the re-winder's gap is given by the next equation, which is based on the vector loop diagram (Figure 10):

$$
\mu_{\mathrm{gap}}=45-\left(\mu_{\mathrm{T} 1}-45\right)-\left(\frac{\mu_{\mathrm{C} 2}}{2}+\mu_{\mathrm{A} 3}\right)
$$

(note that $\mu_{\mathrm{C} 2}$ is divided by two (i.e. to obtain the radius), due to part sensitivity) which is affected by its respective variation given by

$$
\sigma_{\text {gap }}^{2}=\sigma_{\mathrm{T} 1}^{2}+\left(\frac{\sigma_{\mathrm{C} 2}^{2}}{2}\right)+\sigma_{\mathrm{A} 3}^{2}
$$


Table VI. Parts' statistical description

\begin{tabular}{|c|c|c|c|c|c|}
\hline & Parts & Mean & $\sigma$ & $\sigma^{2}$ & Contribution to $\sigma(\%)$ \\
\hline \multirow[t]{4}{*}{$\mathrm{T} 1$} & Bottom/12"/A & 51.8841 & 0.1579 & 0.0249 & 88.51 \\
\hline & Bottom/18"/A & 48.6611 & 0.0595 & 0.0035 & 74.38 \\
\hline & Bottom/12"/B & 51.4850 & 0.0722 & 0.0052 & 77.89 \\
\hline & Bottom/18"/B & 48.2638 & 0.0854 & 0.0073 & 80.64 \\
\hline \multirow[t]{2}{*}{$\mathrm{C} 2$} & Core $\left(12^{\prime \prime}\right)$ & 12.1040 & $* 0.0292$ & 0.0009 & $\ddagger 12.78$ \\
\hline & Core $\left(18^{\prime \prime}\right)$ & 18.1170 & $* 0.0292$ & 0.0009 & $\doteqdot 12.78$ \\
\hline $\mathrm{A} 3$ & Arm & 31.5480 & 0.0059 & 0.0000 & 5.16 \\
\hline \multicolumn{6}{|c|}{ Therefore, from Equations (5) and (6) the resultant gaps are: } \\
\hline & Gap in bottom/12"/A & 0.5159 & 0.1784 & & \\
\hline & Gap in bottom/18"/A & 0.7324 & 0.0800 & & \\
\hline & Gap in bottom $/ 12^{\prime \prime} / \mathrm{B}$ & 0.9150 & 0.0927 & & \\
\hline & Gap in bottom $/ 18^{\prime \prime} / \mathrm{B}$ & 1.1297 & 0.1059 & & \\
\hline & Average gap & 0.8233 & 0.1143 & & \\
\hline
\end{tabular}

Having carried out the preliminary requirements of statistical tolerancing, the means and standard deviations for all the parts were calculated.

From Table VI, it can be seen that the turret's mean differs depending on the core size $\left(12^{\prime \prime}\right.$ or $\left.18^{\prime \prime}\right)$ and spindle (A or B). It can also be noted that between $74 \%$ and $88 \%$ of the variation comes from the turret (T1) factor. Table VI illustrates the impact on the system of the turret variability and mean shift. These results are consistent with those of the sample taken during the multi-vari study. In this case, the combination of core size $18^{\prime \prime}$ and $\mathrm{B}$ turret produces the longest cutting operation time. This is followed by B-12", A-18" and finally A-12". Therefore, from Table VI, it can be concluded that the main source of variability is the turret part (T1). The current limit switch system is not capable of satisfying the specification limits. The improved solution was implemented during the control phase, and is described in the next section.

At the conclusion of the improve phase, the Six Sigma team achieved the following:

- identification of alternative improvement;

- implementation of the best alternative for improving the process;

- validation of the improvement.

\subsubsection{Control phase}

Having identified the root causes of the problem and the possible solutions to reduce the variation of the process, the Six Sigma team moved to the control phase. This phase has the objective of implementing ongoing measures and actions to sustain the improvement by monitoring, standardizing, documenting and integrating the new process on a daily basis ${ }^{17}$.

The solution involves the improvement of the gap by providing the operators with a feedback system. It allows them to understand the optimal turret position and to maintain the turret in that position. The proposed solution consists of installing spirit levels in the extreme of the turret to measure the angle and therefore the gap between the turret and the arm. In this way the operator adjusts the gap according to the water bubble by moving the turret up or down until the bubble is centred. A camera was also installed for operators to observe the water levels from the machine controls. A total of 12 levels were included in the turret in order to satisfy all the combinations of core sizes $\left(10^{\prime \prime}, 12^{\prime \prime}\right.$ and $18^{\prime \prime}$ ), units (top and bottom) and spindles (A and B), which produce different gaps.

2.2.5.1. Process capability. The capability of this improvement was traced by measuring the actual distance when the operator adjusts the gap according to the water levels. The improved system reduces the spindle variability from 0.2568 standard deviation (long term) to 0.074 standard deviation (long term) for all scenarios 
Table VII. Final capability

\begin{tabular}{lll}
\hline & Before & $\begin{array}{c}\text { Improve } \\
\text { spring levels }\end{array}$ \\
\hline DPMO & 115070 & 21311 \\
First pass yield & $88.50 \%$ & $97.87 \%$ \\
Defect ratio & $11.50 \%$ & $2.13 \%$ \\
COPQ (annual) & $£ 58080$ & $£ 10763$ \\
Total savings (annual) & - & $£ 47317$ \\
$\sigma$ long term & 1.2 & 2.03 \\
\hline
\end{tabular}

regardless of spindle, core size or unit. In terms of actual process capability, this is translated to a gap system's sigma level of 2.03, as Table VII illustrates.

In the 10 weeks following the installation of the spirit, 26 failures occurred $(2.13 \%$ defects). This confirmed the strong relationship between the project ' $Y$ ' and the subsystem CTQ gap. The cost of the improvement was a couple of thousand pounds plus Six Sigma team salaries. Therefore, the time to payback of the solution is less than one month.

2.2.5.2. Control plan. The intent of an effective control plan strategy is to operate the temporal or sustained solutions consistently, on target, with minimum variation and while minimizing process over-adjustment. It also helps to assure the identified and implemented process improvements become institutionalized by providing adequate training in all procedures.

The candidate variable to be controlled is the gap, since the output variation is a function of the gap variation. A control plan, which indicates the target values, specifications limits and standard deviation expected for this critical to quality characteristic, was put in place. The designated control method consists of a standard operation procedure (SOP) with reaction plan. The SOP document describes how to perform the operation utilizing the spirit levels. In addition, it describes the reaction plan in case of failure by explaining how to readjust the spirit level. The proposed solution is considered by itself a mistake proofing solution, because it reduces the ambiguity of the operator criterion of deciding using the naked eye what is the optimal gap. At the end of the control phase, the improved process was institutionalized and its ongoing performance was monitored. The Six Sigma team made the transition of the process back to the process owner. This project was completed in the timescale established and was closed eight months after the initialization date.

\section{CONCLUSIONS}

Although Six Sigma is gaining wider acceptance in organizations today, it is difficult to find a detailed case study of Six Sigma approaches in the current literature. Some attempts have been made ${ }^{5}$. This paper presented a real case study illustrating the effective use of Six Sigma to reduce waste in a continuous film line. It illustrates in detail how the project was selected, and how the define, measure, analyse, improve and control phases of the Six Sigma DMAIC methodology were carried out. Several tools and techniques were employed during the course of the project.

The success of this Six Sigma case study can be attributed to the following key factors:

(1) Six Sigma methodology is an effective problem solving strategy;

(2) management involvement and commitment;

(3) project selection and its link to business goals;

(4) training and teamwork;

(5) project progress tracking and monitoring. 
As a result, significant financial benefit was achieved in a relatively short period of time. This allowed material waste to be reduced by nearly 50000 per year. In addition, the waste reduction created a chain reaction in which runtime was increased, quality was improved and inspection reduced. Additional minor benefits were perceived, including employee participation in Six Sigma projects, an increased process knowledge and use of statistical thinking to solve problems. The rapid payback of the project motivated people at the company to implement more Six Sigma projects. Additional projects were selected based on the cluster of ideas produced during the initial project selection exercise.

\section{Acknowledgements}

This research has been funded by the Mexican Council of Science and Technology, CONACYT. Special thanks to Noel Byrne, Adrian Barnes and Karen Vyse. The authors would also like to thank the reviewers for their invaluable suggestions and constructive comments in improving the paper.

\section{REFERENCES}

1. Linderman K, Schroeder R, Zaheer S, Choo A. Six Sigma: A goal-theoretic perspective. Journal of Operations Management 2003; 2:193-203.

2. Henderson K, Evans J. Successful implementation of Six Sigma: Benchmarking General Electric Company. Benchmarking and International Journal 2000; 7:260-281.

3. Antony J, Bañuelas R. Six Sigma a business strategy for manufacturing organisations. Manufacturing Engineering $2001 ; 8: 119-121$.

4. Goh T. A strategic assessment of Six Sigma. Quality and Reliability Engineering International 2002; 18:403-410.

5. Rasis D, Gitlow H, Popovich E. Paper Organisers International: A fictitious Six Sigma green belt case study: I. Quality Engineering 2002; 15:127-145.

6. Meredith J, Mantel S. Project Management. Wiley: New York, 2000.

7. Brue G, Launsbry R. Design for Six Sigma. McGraw-Hill: New York, 2003.

8. Shephered F. Modern Coating Technology Systems. Maclaren: Barnet, U.K., 1994.

9. Breyfogle F, Cupello J, Meadows B. Managing Six Sigma. Wiley-Interscience: New York, 2001.

10. Nave D. How to compare Six Sigma, lean and the theory of constraints. Quality Progress 2002; 35:3.

11. Huber C. Straight talk on DFSS. Six Sigma Forum Magazine 2002; 1:20-25.

12. Berryman M. DFSS and big payoffs. Six Sigma Forum Magazine 2002; 2:23-28.

13. Porter L. Six Sigma excellence. Quality Word 2001; 1:12-15.

14. George M. Lean Six Sigma. McGraw-Hill: New York, 2002.

15. Eckes G. The Six Sigma Revolution. Wiley: New York, 2001

16. Bañuelas R, Antony J. Critical success factors for the successful implementation of Six Sigma project in organisations. The TQM Magazine 2002; 14:92-99.

17. Pande P, Neuman R, Cavanagh R. The Six Sigma Way: How GE, Motorola and Other Top Companies are Honing their Performance. McGraw-Hill: New York, 2000.

18. Breyfogle F. Implementing Six Sigma: The Smarter Solutions Using Statistical Methods. Wiley: New York, 1999.

19. Kiemele M, Schmidt S, Berdine R. Basic Statistics: Tools for Continuous Improvement. Air Academic Press: Colorado Springs, CO, 1997.

20. Bicheno J. The Quality 50. Picsie Books: Buckingham, U.K., 1994.

21. Montgomery D, Runger G. Applied Statistics and Probability for Engineers. Wiley: New York, 2003.

22. Pyzdek T. The Six Sigma Handbook. McGraw-Hill: London, 2001.

23. Ishikawa K. Guide to Quality Control. Asian Productivity Organisation: Tokyo, Japan, 1974.

24. Waddick P. Six Sigma DMAIC quick reference. ISIX SIGMA. http://www.isixsigma.com [26 October 2002].

25. Antony J. Design of Experiments for Engineers and Managers Using Simple Graphical Tools. Butterworth/Heinemann: Oxford, 2003.

26. Eckvall D, Juran J. Manufacturing planning. Quality Control Handbook, Juran J, Gryna F, Bingham R (eds.). McGraw-Hill: New York, 1974.

27. Harry M. The Vision of Six Sigma. Sigma Publishing Company: Phoenix, AZ, 1994. 


\section{Authors' biographies}

Ricardo Bañuelas is currently reading for a doctorate in Quality Engineering at the University of Warwick. $\mathrm{He}$ has a first degree in Industrial Engineering and a Master degree in Manufacturing Systems Engineering. He has implemented Six Sigma in several organizations in the U.K. and Mexico. The areas of study of his doctorate are Six Sigma and Design for Six Sigma, the stochastic analytic hierarchy process and operations research.

Jiju Antony is currently leading the Six Sigma and Process Improvement Research Centre at the Division of Management, Caledonian Business School, Glasgow Caledonian University, Scotland. He worked as Senior Teaching Fellow at the Warwick Manufacturing Group of the University of Warwick till September 2003. He received a BE in Mechanical Engineering from the University of Kerala, South India, an MEngSc in Quality and Reliability Engineering from the National University of Ireland and a PhD in Quality Control for Manufacturing from the University of Portsmouth, U.K. His work experience includes 2 years as a maintenance engineer, 3 years as a quality/reliability engineer and 6 years as a quality engineering consultant for an number of multi-national companies. He has published over 80 papers and three textbooks in the areas of reliability engineering, design of experiments, Taguchi methods, total quality management, statistical process control, Six Sigma and service quality. His primary research areas include design of experiments and Taguchi methods for improving process quality, robust design for new product development process, statistical process control for variability reduction, problem solving using quality tools and techniques and Six Sigma for both manufacturing and service processes. He is the Editor-in-Chief of the International Journal of Six Sigma and Competitive Advantage.

Martin Brace is a certified Black Belt. He has implemented, trained and led Six Sigma projects across a variety of business units within a multinational company. He holds a first degree in Manufacturing Systems Engineering and he is currently a product supply manager. 